\title{
Tendencias formativas en Educación Especial en Iberoamérica
}

Training Trends in Special Education in Ibero-America

Tendências formativas em Educação Especial na Ibero-América

\section{Lady Meléndez-Rodríguez* (iD orcid.org/0000-0001-5142-6755}

Para citar este artículo: Meléndez-Rodríguez, L. (2020). Tendencias formativas en Educación Especial en Iberoamérica. Revista Colombiana de Educación, 1(79), 325-346. https://doi.org/10.17227/rce.num7910351

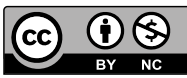

Recibido: 27/07/2019

Evaluado: 13/09/2019

* Doctora en Educación. Docente investigadora del Programa Latinoamericano de Doctorado en Educación de la Universidad de Costa Rica, San José, Costa Rica.

Correo electrónico: lady.melendez@ucr.ac.cr 


\begin{abstract}
Resumen
El presente artículo comprende el texto de la conferencia inaugural del // Encuentro Educación y Discapacidad. Perspectivas Investigativas y Formación Docente, que se llevó a cabo del 6 al 9 de noviembre del 2018, en la Universidad Pedagógica Nacional en Bogotá, Colombia. Corresponde a una reflexión fundamentada en un análisis bibliográfico y vivencial, que asiste al propósito de preguntarse acerca del presente y futuro de la formación en Educación Especial, en tanto constituye un campo de conocimiento y acción docente en franca transición para Iberoamérica. Históricamente, la Educación Especial ha sido definida en función de la atención educativa dirigida - específicamente- a personas con discapacidad y con necesidades educativas especiales; que, desde el enfoque de la educación inclusiva, ahora reclaman su derecho a estar presentes, participar y aprender con equidad y calidad, con sus pares y en el contexto mismo de la educación ordinaria. Esto amerita docentes capaces de diseñar y aplicar apoyos educativos específicos en atención a una lectura crítica, propositiva y flexible del contexto, sus demandas y relaciones. Entre las principales conclusiones de esta reflexión es posible decir que, en Iberoamérica, dependiendo de sus antecedentes, la Educación Especial puede entenderse como impulsora u obstáculo para la educación inclusiva, que cada país vive su propio nivel de inclusión educativa, reflejado en los procesos de formación del docente de apoyo, los que no necesariamente obedecen a perfiles profesionales unificados, prolijos ni debidamente validados.
\end{abstract}

\section{palabras clave}

educación especial; formación docente; apoyos educativos específicos; educación inclusiva; perfil profesional

\section{Keywords}

special education; knowledge base for teaching; resource room programs; inclusion; teacher qualifications

\begin{abstract}
This article comprises the text of the inaugural conference of the II Meeting on Education and Disability. Research Perspectives and Teacher Training, which took place from $6^{\text {th }}$ to $9^{\text {th }}$ November 2018, at the Universidad Pedagógica Nacional in Bogotá, Colombia. It corresponds to a reflection based on a bibliographical and experiential analysis, which attends the purpose of asking about the present and future of training in Special Education, as it constitutes a field of knowledge and teaching action in actual Transition for Ibero-America. Historically, Special Education has been defined in terms of targeted educational attention -specifically- to people with disabilities and special educational needs. That, from the approach of inclusive education, now demand their right to be present, participate and learn with equity and quality, with their peers and in the context of ordinary education. This deserves teachers capable of designing and applying specific educational supports, in attention to a critical, propositive and flexible reading of the context, their demands and relationships. Among the main conclusions of this reflection, it is possible to say that, in Ibero-America, depending on its antecedents, Special Education can be understood as a driving force or obstacle for inclusive education, that each country lives its own level of inclusive education, reflected in the training processes of the teacher of support, which do not necessarily comply with professional profiles uni-

fied, neat or duly validated.
\end{abstract}

\section{Resumo}

Este artigo inclui o texto da conferência de abertura da II Reunião sobre Educação e Deficiência. Perspectivas de pesquisa e formação de professores, que ocorreram de 6 a 9 de novembro de 2018, na Universidade Pedagógica Nacional em Bogotá, Colômbia. Corresponde a uma reflexão baseada em uma análise bibliográfica e experiencial, que serve para perguntar sobre o presente e o futuro da formação em Educação Especial, pois constitui um campo de conhecimento e ação de ensino em franca transição para a Ibero-América. Historicamente, a Educação Especial foi definida em termos de atendimento educacional direcionado especificamente a pessoas com deficiência e com necessidades educacionais especiais que, do ponto de vista da educação inclusiva, reivindicam seu direito de estar presente, participar e aprender com equidade e qualidade, com seus pares e no contexto da educação comum. Isso merece professores capazes de projetar e aplicar suportes educacionais específicos, atentos a uma leitura crítica, proposicional e flexível do contexto, suas demandas e relacionamentos. Dentre as principais conclusões dessa reflexão, é possível afirmar que, na América Latina, dependendo de sua formação, a Educação Especial pode ser entendida como um condutor ou obstáculo à educação inclusiva, que cada país vive seu próprio nível de inclusão educacional, refletido nos processos de apoiar a formação de professores, que não segue necessariamente perfis profissionais unificados, detalhados ou devidamente validados.

\section{Palavras-chave}

educação especial; formação de profesores; apoio educacional específico educação inclusiva; perfil profissional 


\section{Introducción}

Las demandas por una educación inclusiva de los últimos tiempos y su encuentro con el movimiento por una atención educativa a la diversidad han trastocado la historia de la Educación Especial en el mundo, sobre todo en su versión tradicional. La cual es definida como el conjunto de servicios y recursos de apoyo educativo para las personas con discapacidad y con necesidades educativas especiales de distinta naturaleza, aunque en algunos países incluye a las personas con capacidades sobresalientes o excepcionales.

Dichos argumentos tienen urgencia de una reflexión profunda y amplia por parte de todos los sectores relacionados con esta disciplina. Por lo que, tanto su concepción ontológica, sus principios epistemológicos y éticos, hasta la forma en que se disponen los servicios de Educación Especial en cada país y, por supuesto, las ofertas de formación de quienes asumen educativamente estos servicios ameritan ser repensados y razonablemente transformados de cara a las demandas histórico culturales de nuestro tiempo.

Una reflexión tal, parece superar a la ejercida en otros momentos para atender las corrientes de movimientos paradigmáticos, como lo fue el de integración educativa, en tanto los alcances de la educación inclusiva y de la atención educativa a la diversidad sobrepasan los linderos que hasta ahora han contenido a la Educación Especial, a su objeto de estudio y a su objeto de la profesión y del trabajo. Estos se han descentrado en la actualidad para dar paso a algo más complejo e inasible, que aún no logra delimitarse en la geografía de las disciplinas ni tampoco en las ofertas para una formación docente con pertinencia y calidad.

No obstante, cabe decir, que los planes de formación que plantean ofertas recientes más progresistas, ante la imposibilidad de asumir todo lo que se refleja en tal complejidad, han optado por recortar su propio espacio de acción, intentando echar a andar un curriculum consecuente con sus principios y enfoques, su coincidencia con la educación inclusiva y la atención educativa a la diversidad para formar a los futuros docentes de la Educación Especial. Lo que ha generado un trabajo colaborativo, quizás sin precedentes, en el diseño curricular para la formación profesional.

Por esa razón, este documento más que una declaración de conocimiento pretende constituirse en una provocación hacia el trabajo conjunto por la develación de un perfil profesional de la Educación Especial más acorde con las exigencias del contexto socio cultural en el que nos ha tocado vivir. Perfil que nos obliga a empezar por cuestionarnos acerca del ser de nuestro referente fundacional: ¿qué es hoy la Educación Especial?

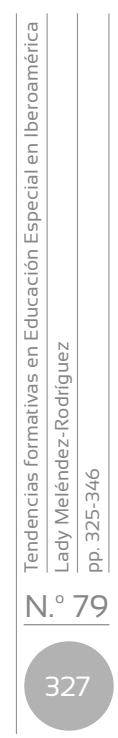




\section{La Educación Especial y su episteme}

Cuando se entiende a la Educación Especial como un campo de estudio, desde el que es posible derivar estudiosos del tema o epígonos disciplinares en calidad de expertos en una episteme u objeto de conocimiento preciso y particular, nos encontramos con los primeros problemas epistemológicos.

Al respecto, rara vez localizamos una definición de la Educación Especial que en su inicio diga que se trata de la rama del conocimiento que se dedica a..., como se espera en el caso de cualquier disciplina. En ese sentido, al menos en la actualidad, no es fácil hacerse con su objeto de conocimiento. No existe, en este momento, ese algo para la Educación Especial que sea, por ejemplo, lo que la materia es a la Física, el ser vivo a la Biología o la cultura a la Antropología. Situación que dificulta determinar a qué debe dedicarse la Educación Especial, qué la define como disciplina y, por lo tanto, en qué deben ocuparse sus profesionales y qué deben contener los planes de formación de los futuros educadores y educadoras especiales. O, en su defecto aceptar, como otros igual defienden, que la Educación Especial es una disciplina en extinción (Florin, 2014).

En cualquier parte del mundo la Educación Especial suele definirse a partir de lo distinto a la Educación Regular, la educación que se inventó para aquellos que, por diversas razones, era necesario separar de la educación ordinaria. Así, palabras más, palabras menos, es usual identificar a la Educación Especial como el "conjunto de apoyos y servicios a disposición de los alumnos con necesidades educativas especiales, ya sea que los requieren temporal o permanentemente" (MEP, 2005). Lo que sugiere la referencia más a una práctica o a una tecnología que a una disciplina.

Tal definición permite inferir que el educador especial es solo el experto en esos apoyos y servicios. Conclusión simple con la que muchos no estarán de acuerdo, ya que los profesionales en este campo se ven también llamados a llevar a cabo evaluaciones, diagnósticos e interacciones personales, educativas, familiares, comunitarias y laborales, además de actualizaciones permanentes, investigaciones en diversos temas y movimientos de afiliación por los derechos de las personas con discapacidad así como participaciones en equipos transdisciplinares, entre otras múltiples tareas que, en su conjunto, además de trascender significativamente la idea de lo que hace un manejador de apoyos específicos, se trata de competencias difíciles de encontrar incluso en profesiones cercanas. Pero esto parece valer poco para quienes, a la luz de los últimos acontecimientos por la inclusión, se preguntan si más bien la Educación Especial debe mutar o desaparecer. ¿Por qué?

En este momento es posible identificar cuatro posiciones con respecto a la Educación Especial en el mundo: 
» Nada ha cambiado: Hay países y localidades donde aún la atención educativa a personas con discapacidad se sigue haciendo desde una visión segregada, mediante centros y servicios específicos identificados desde la deficiencia y el modelo clínico. En estos casos, la Educación Especial continúa siendo necesaria y tanto la organización de servicios como la formación de profesionales en este campo se ofrece desde ese mismo modelo. (Castillo, et ál., 2018).

» En discusión: Los países que rectificaron su dirección hacia la integración en los años 80 y, más recientemente, hacia una quisquillosa educación inclusiva que no acaba por consolidarse de manera estructural discuten ampliamente sobre el papel de la Educación Especial. Estos suelen justificar los servicios específicos para las personas que requieren apoyos extensos y generalizados, así como las ayudas didácticas y tecnológicas que ofrecen los educadores especiales desde su rol de docentes de apoyo para el contexto de la educación regular y nuevos espacios alternativos para el ejercicio de la profesión. Tienen en común que la Educación Especial ha funcionado como guía principal hacia la inclusión educativa, no solo de las personas con discapacidad sino de aquellas que por razones personales y culturales han sido históricamente relegadas del derecho a la educación.

Ese rol de liderazgo tiene a los países en discusión permanente acerca de si debe ser la Educación Especial la que continúe orientando los apoyos o si — desde una visión inclusiva - las tareas actuales del educador especial pueden y deben ser asumidas por educadores regulares. Entonces, ¿en qué deben convertirse los servicios y educadores especiales? ¿Qué tipo de formación y capacitación debe darse a docentes para que asuman una atención educativa con equidad y calidad en sus centros y salones de clase? La discusión se mantiene mientras prevalece en los planes de formación docente una conceptualización cercana a la educación inclusiva y a la atención educativa a la diversidad para futuros educadores que siguen apellidándose de Educación Especial y que atenderán, por el momento, servicios educativos que se acercan más a la integración que a la inclusión educativa (Castillo, et ál., 2018).

» No a la Educación Especial: Las sociedades más antiguas, como es el caso de la ibérica, que reportan los albores de la Educación Especial a inicios del Renacimiento, tienden a asociarla con las formas más drásticas de segregación y, así, Ilegan a tildarla como la antítesis de la inclusión, al punto de considerar que depende de su desaparición que la educación inclusiva realmente prospere. Esta posición considera que la escuela ordinaria es el mejor lugar para que todos aprendan juntos, por lo que aluden a una 
educación estratégicamente colaborativa, que desde el Diseño Universal para el Aprendizaje se ofrezca una enseñanza que resulte efectiva y equitativa para todos quienes aprenden. Razón por la cual, tanto la formación como la práctica docente, además de la gestión y la organización escolar en todos los niveles, deben viajar en la misma dirección (Echeita, 2016). De tal manera, este constituye un entorno en el que ni los servicios específicos ni los educadores especiales parecen tener cabida alguna.

La educación finesa: Trato aparte merece la Educación Especial en Finlandia, dado que, como explican Sabel, Saxenian, Miettinen, Hull y Hautamäki (2010), la educación finesa debe su calidad y éxito en pruebas internacionales - Como PISA- a la Educación Especial. La capacidad de detectar y prevenir dificultades de aprendizaje antes de que estas ocurran, así como la capacidad de dar atención a estas en el contexto escolar, gracias a la coordinación de recursos profesionales y familiares, han permitido a Finlandia revelar en PISA y en muchas otras evaluaciones, que un mayor número de estudiantes alcanza buenos niveles de formación y que los más aventajados suben el listón de logro al nivel más alto esperado. Por esa razón, la educación finesa defiende la existencia de los servicios de Educación Especial, así como la formación docente en esta disciplina desde un enfoque inclusivo, ya que depende de esta para conservar su destacado lugar a nivel mundial.

A juzgar por las posiciones mencionadas, no contamos hoy día con una Educación Especial única, sino que se ha hecho relativa al nivel de desarrollo que la educación inclusiva haya alcanzado en cada contexto. Sin embargo, es urgente destacar los principales riesgos que esta transición está trayendo en algunas sociedades, donde las decisiones no se están tomando armónicamente. El primero, y más peligroso, tiene que ver con las personas que por su condición requieren apoyos extensos y generalizados, para quienes el DUA, el aprendizaje colaborativo ni las competencias del docente regular, son aun suficientes para colocarlas en condiciones de equidad en los ambientes educativos ordinarios; sienten estar fracasando lo mismo que sus maestros y no les quedan espacios alternativos ni apoyos más específicos que les den la oportunidad de un proceso inclusivo más paulatino y dosificado razonablemente ajustado a las características de cada situación. Con lo que, irónicamente, pareciera ser la educación inclusiva la que deja a estas personas sin posibilidad de aprender adecuadamente.

El segundo riesgo lo padece un grupo importante de educadores especiales en ejercicio y los que están formándose desde esta especialidad, quienes no encuentran un lugar en el registro de las profesiones, como es 
el caso de Colombia (Vélez, 2016), razón por la que ven restringidas sus oportunidades de contratación y trastocadas sus condiciones laborales, gremiales $y$, por supuesto, personales. Al respecto, cabe preguntarse si con el advenimiento de la educación inclusiva desapareció el objeto de la profesión de la Educación Especial y se transformó o si fue asumido por otra profesión. El problema más serio es que el objeto de la profesión siga existiendo sin que alguien lo asuma con la eficiencia y el cuidado que merece.

Y un tercer riesgo consiste en que, si son las formas de apoyo inclusivas y aquellas preventivas de las barreras para el aprendizaje las que están señalando el camino de la calidad y del éxito a la educación ordinaria, quienes están clausurando la Educación Especial se estarían negando esa oportunidad.

\section{La Educación Especial en el contexto de la educación inclusiva}

Las estadísticas actuales y proyectadas relacionadas con nivel educativo y calidad de vida, demuestran que el desarrollo humano individual y social depende de que las personas alcancen un mayor nivel educativo y que la educación que reciban sea pertinente y de calidad; además de que, cuanto más alto sea el número de personas involucradas en este tipo de educación, mayor índice de desarrollo humano alcanza un país. Por lo tanto, es posible decir que no hay una sola dimensión del bienestar de las personas que no esté relacionada con una mejor educación.

En otras palabras, condiciones aceptables de inclusión social y laboral, salud, equidad de género, mortalidad materna e infantil, nutrición, inmunización, esperanza de vida al nacer, desarrollo económico, resolución pacífica de conflictos y sostenibilidad ambiental se deben inexorablemente a un incremento en la inversión social en educación, a una adecuada gestión de esa inversión y a lo que esta puede significar en cuanto a campañas de alfabetización, programas de subsidios, así como de enriquecimiento y flexibilidad curricular. Y, más allá, la formación y actualización profesional de educación terciaria y de proyección de los centros educativos hacia las comunidades.

Es posible identificar los primeros fundamentos por la educación inclusiva, aunque no precisamente con ese nombre, en la medida en que se concibe a la educación como un derecho en la Declaración Universal de Derechos Humanos (1948), principalmente en su Artículo 26, que establece el derecho a la educación gratuita para todos, la igualdad en la educación superior y el encuentro del desarrollo humano por esta vía. Principios que se reiteran en posteriores declaraciones como la Convención

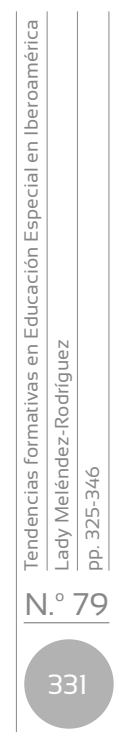


relativa a la Lucha contra las Discriminaciones en la esfera de la Enseñanza (1960), la Convención sobre la eliminación de todas las formas de discriminación contra la Mujer (1979), la Convención sobre los Derechos del Niño (1989), la Convención de Derechos de las Personas con Discapacidad (2006) (CDPD) y, más recientemente, la Declaración de las Naciones Unidas sobre los Derechos de los Pueblos Indígenas (2007) además de la Resolución de la Asamblea General de las Naciones Unidas sobre el Derecho a la Educación en Situaciones de Emergencia (2010).

Con una enunciación directa se constituyen en derroteros fundamentales, además de la Declaración de Educación para Todos (Unesco, 1990), otros varios que han elevado la discusión por una educación inclusiva donde inicialmente se abogaba por la educación para algunos grupos en condición de vulnerabilidad hasta que, actualmente, se habla de una transformación total de los sistemas educativos hacia sistemas educativos inclusivos.

Con ese propósito identificamos el Acuerdo de Mascate (Unesco, 2014) en el que se pone énfasis en los Objetivos de Desarrollo Sostenible y donde el $\mathrm{ODS}_{4}$ demanda "Garantizar una educación inclusiva, equitativa y de calidad y promover oportunidades de aprendizaje durante toda la vida para todos"; además de establecer a la educación como requisito inexcusable para el cumplimiento de los otros ODS, con plazo al 2030. Los requerimientos y orientaciones de este Acuerdo se trasladan y amplían en la Declaración de Incheon (2015), y para América Latina se habían plasmado ya con mayor contextualización en la Declaración de Lima (Unesco, 2014), donde se refuerza la necesidad de "una educación inclusiva para todos, con equidad, relevancia, pertinencia y que garantice la sostenibilidad desde la atención y estimulación temprana hasta la terciaria así como un aprendizaje a lo largo de la vida". Esta Declaración expresa, adicionalmente, la demanda por "un desarrollo profesional continuo, la participación de las familias, el desarrollo de habilidades para un trabajo decente y una vida digna en ambientes seguros, saludables e inclusivos". Así, demarcado el terreno, los gobiernos deben hacer lo que esté a su alcance para cumplir tales compromisos, dado que es urgente recuperar los 50 años de rezago, mencionados en la Declaración, para poder acercarnos al cumplimiento de los objetivos de Incheon para el 2030.

En ese sentido, es necesario reconocer que las personas con discapacidad han sido las más excluidas de todas y que su condición solo puede entenderse desde la interseccionalidad, en tanto su condición se ve repetidamente atravesada por otras como la discriminación por género, la pertenencia a grupos étnicos desfavorecidos y el hecho de habitar en espacios económicamente deprimidos. Por desgracia, la probabilidad de que estas condiciones se confabulen para actuar en contra de la inclusión social de los menores de los países de bajo y mediano desarrollo es alta. 
De la población de la región que está fuera de las escuelas (35,5 millones) la tercera parte corresponde a personas con discapacidad que se encuentran entre los 3 y los 18 años de edad. A lo que se suma que menos del $5 \%$ de la población con discapacidad que ingresa a la escuela logra concluir la primaria (Inclusión Internacional/Inico, 2009). Esto deja en evidencia que de las poblaciones excluidas de la educación en América Latina las personas con discapacidad son las más afectadas. Y, entre estas, las personas con discapacidad intelectual han sido y son las más excluidas de la educación en América Latina, el Caribe y el resto del mundo (Inclusión Internacional, 2006) (En Meléndez, 2010, p. 6)

Por lo tanto, el imperativo por la educación inclusiva demanda que sea la inclusión educativa de las personas con discapacidad y con necesidades educativas especiales el principal esfuerzo por hacer. Pero es necesario dejar claro que cuando se habla de educación inclusiva no se hace referencia al facilismo curricular ni a la interacción piadosa con las personas con discapacidad en los centros regulares; se trata de que todos y todas desarrollen, en condiciones de equidad y calidad, aptas competencias para la inclusión social y laboral de acuerdo con sus talentos y posibilidades en común con sus compañeros, educadores y familias, desde un enfoque sostenible y solidario; lo que debe ser comprendido por los futuros educadores especiales.

El papel de la Educación Especial implica entonces que

[...] debe reorganizarse a la educación en general y leer allí a la educación especial, al educador especial y, por lo tanto, sus necesidades de formación, actualización y desarrollo profesional. Donde la educación especial no sea tampoco la reparadora de los yerros de la educación regular, sino que acompañe una mejor respuesta de la educación regular a todo el estudiantado, mediante programas efectivos de interacción pedagógica, que alcancen hasta a los estudiantes que requieren apoyos extensos y generalizados. En otras palabras, la educación especial debe ser uno de esos motores que lleve al país a cumplir sus ideales y compromisos relacionados con la inclusión en la equidad de oportunidades hacia el desarrollo humano de todos los habitantes (Castillo, et ál., 2018, p. 27)

Así, cuando los estudiantes que requieren apoyos educativos específicos — cualquiera que sea la causa - lleguen al centro educativo, deben ser recibidos por todos sus maestros, incluyendo al educador especial transformado en figura esencial de apoyo, para asegurarles una estadía educativa altamente exitosa. Lo que implica un trabajo hombro a hombro del educador ordinario con el educador especial, un trabajo respetuoso, solidario y de mutuo reconocimiento profesional. 
No obstante, aun cuando se aceptan las demandas mencionadas, no es posible hablar todavía de un modelo latinoamericano de educación inclusiva, sino más bien de prácticas y acciones desiguales en la región. Por ejemplo, como se confirma actualmente por varios autores en Vargas y Alves, coords. (2016):

[...] mientras Chile mantiene distintas formas de atención y promueve la educación inclusiva, hace un peso incómodo sobre el tema del déficit para salvar la asignación de recursos por parte del Estado. México habla de una inclusión incipiente, pero sus argumentos están más anclados en las medidas integracionistas de atención a personas con discapacidad. Colombia, en cambio, ha hecho una producción impecable de materiales para orientar la educación inclusiva en ese país, pero la resistencia por reconocer con equidad la participación de docentes de apoyo ha frenado significativamente la vivencia de la inclusión en las escuelas. Y, Costa Rica respira educación inclusiva en todos sus estatutos, pero condiciones estructurales inamovibles la han llevado a conformarse con buenas prácticas de centros que han logrado salvar esas barreras no con poca dificultad y con perseverancia tenaz. A lo que cabe agregar que, en la región, hay países que apenas y ofrecen los servicios más elementales para niños con discapacidad, como es el caso de Honduras, y otros como Guatemala que aleccionan sobre cómo acercarse a la educación inclusiva desde la Rehabilitación Basada en la Comunidad impulsada por las familias, pero con poco desarrollo en cuanto a decisiones y acciones propiamente escolares (Meléndez, 2016, pp. 8-9).

Por lo tanto, si la educación inclusiva toma opción por quienes, dadas sus diferencias, han sido históricamente excluidos del derecho a educarse, lo que habla además de una atención educativa a la diversidad, la Educación Especial debe ser capaz de leer el nivel de educación inclusiva que se vive en un contexto determinado y debe impulsarla cada vez hacia el paso siguiente en lo que tiene que ver con la inclusión de personas con discapacidad y, en general, con personas que requieren apoyos educativos específicos. Por lo anterior, la Educación Especial y la educación inclusiva deben trabajar juntas en perfecta sintonía. Esta heurística debe ser estrictamente asumida por los centros de formación docente para enseñar a los futuros educadores especiales sobre cómo desarrollar su profesión desde la educación inclusiva y para un contexto determinado.

Como explican Meléndez y Hernández (2016) la educación inclusiva no se decreta, sino que se vive y se convive a partir de valores, actitudes y decisiones personales, lo que no es posible movilizar con base en imposiciones sino más bien en convicciones. Con este enunciado queremos decir que, si bien las políticas por la inclusión nos permiten soñar con una condición ideal de transformación macrosocial en esa dirección, en 
tanto la inclusión parte de una convicción y se realiza en una práctica viva, las políticas solas son insuficientes de por sí en caso de que no trabajemos para hacer de la inclusión una realidad. Pero es necesario dar a conocer también que la naturaleza propia de la inclusión hace que, aun cuando no existan políticas en su favor, la intención de las organizaciones sociales puede hacerla posible; ya que esa misma característica nos permite proyectar que, mientras nos encontramos con esas políticas, cada organización puede ir construyendo lo propio para hacer de su cultura y servicio una convivencia inclusiva.

En ese sentido, es necesario comprender a quién corresponde desarrollar la educación inclusiva desde los contextos educativos y, por lo tanto, a quiénes y cómo se debe formar para ejercer la educación inclusiva. Lo que implica que es necesario preguntarse también cuál es el papel de la Educación Especial en función de la educación inclusiva o si aquella más bien entorpece su desarrollo, como se cree en España y en algunos otros países (Echeita, 2016).

\section{La Educación Especial en el contexto de la atención educativa a la diversidad}

Es necesario entender la atención educativa a la diversidad como la forma en que se concreta la educación inclusiva en los espacios educativos. De acuerdo con Cicerón (106 a.C.), la diversidad es la razón congruente con la naturaleza de las cosas y, en nuestro caso, es la naturaleza de los seres humanos en tanto cosas naturales. Lo que nos permite aprender de otros seres vivos que la diversidad es "una condición de la vida en comunidad, cuyos procesos vitales se relacionan entre sí y se desarrollan en función de los factores culturales de un mismo ambiente. Donde, tanto relación como variedad aseguran y potencian la vida de todos los habitantes de esa comunidad" (Meléndez, 2004, p. 3).

Por lo que el secreto de la supervivencia de nuestra especie no está en la norma sino en las diferencias, y así, en las diversas formas de crear conocimiento, modos y medios de resolver los problemas de la humanidad. Pero, adversamente, hemos creado formas de enseñar y aprender, por lo tanto, formas de vivir desde una normalización forzada que obliga a tratar de acabar con las diferencias. De forma tal, que la escuela de inicios del S. xx, fundamentada en la psicometría, se encargó de organizarnos bajo una norma y, en adelante, de establecer un curriculum que debía ser asimilado por esa norma y que, a través de mediciones, dejaba fuera a quienes no accedían a esa posibilidad. Y este es el modelo de escuela que se ha seguido hasta hoy; o sea, un modelo de escuela contra natura. En este momento, el movimiento de atención educativa a la diversidad es un

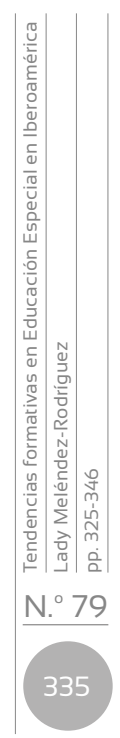


movimiento reivindicatorio de una forma de educación que se ajuste a nuestra propia condición humana personal y cultural, donde el derecho a la educación pueda ser equitativamente ejercido por todos y no solo por quienes se acomodan a la norma.

Intentar llegar a todos mediante un trato igualitarista (normalizado) implica ofrecer una educación excluyente, en la medida en que pone al soslayo las diferencias que humanamente nos definen como personas y como culturas. Por lo tanto, a la diversidad le subyace la legitimación de las diferencias personales y culturales, las diferencias definen nuestras identidades y todas las identidades ostentan igual valor humano. En ese sentido, no son las diferencias las que determinan un trato injusto, sino el desigual valor con que se asumen. Y, a menor valor atribuido menor inclusión en las oportunidades de desarrollo humano; a mayor valor atribuido, más posibilidades de contar con oportunidades de desarrollo humano (Meléndez, 2004).

Al respecto, cabe decir que desde que la Unesco promovió su consigna de Educación para Todos en Tailandia en 1990, hasta la inclusión del oDs4 en la Agenda 2030 de la onu. Queda claro que ese Todos refiere, enfáticamente, a quienes históricamente han sido excluidos de las oportunidades de desarrollo humano porque, por razones personales y culturales, han quedado fuera de las posibilidades de educarse.

En otras palabras, "Educación para Todos y Garantizar una educación inclusiva, equitativa y de calidad, y promover oportunidades de aprendizaje durante toda la vida para todos" (Unesco, 2015), demanda que nadie debe quedar excluido de una educación eficiente para remontar las carencias hacia el desarrollo y que esa educación debe calzar asertivamente para cada una de las identidades, personales y culturales que ocupan un válido lugar en ese Todos.

Y en ese contexto, entonces, ¿qué papel juega la Educación Especial?

La Educación Especial nació y se institucionalizó para dar enseñanza a aquellas personas que, por su discapacidad, no eran aceptadas en las escuelas ordinarias. Así, se estableció una educación que se brindaba en hospitales o instituciones de caridad para residentes vitalicios con discapacidad y, de forma también segregada, en centros específicos hasta la primera mitad del S. xx. Más adelante, con el movimiento de integración educativa, en atención al principio de normalización, se consideró que las personas con discapacidad tenían derecho a educarse en escuelas de su comunidad a las que asistían sus hermanos y pares; con ello nacen las aulas especiales dentro de escuelas ordinarias y los programas individualizados para estudiantes con discapacidad integrados en aulas ordinarias. Servicios atendidos, principalmente, por educadores especiales capacitados o formados en métodos y técnicas específicos de atención (Meléndez, 2016). 
Hasta entonces, los procesos de formación de educadores especiales se ajustaron a metodologías emergentes y diversos espacios laborales, pero siempre asumiendo que su objeto de estudio y de trabajo era la atención educativa a la persona con discapacidad, que se amplió luego hacia las personas con necesidades educativas especiales por razón o no de discapacidad. Lo que permitió a algunos países incluir también a la población con talentos o capacidades sobresalientes y excepcionales, como fueron los casos de México y Colombia.

Más recientemente, el movimiento por la educación inclusiva demanda que todas las formas de educación deben enfilarse hacia la evitación de la exclusión social y cultural de todos quienes aprenden, incluidas las personas con discapacidad. Por lo que la discapacidad se erige como un conjunto más de manifestación de las diferencias y una educación para la diversidad debe ser capaz de asumirla como a cualquier otra expresión de la diferencia. Razón que trastoca todas las formas de organización escolar, pero también a la pedagogía y a la didáctica tradicionales y, como reflejo, a la formación de los educadores que deberán hacerse cargo de esa transformación.

Lo anterior despierta el cuestionamiento acerca de si la Educación Especial debe seguir existiendo, como respalda Florin (2014), y, si es así, a quién debe atender el educador especial, de qué manera y dónde, para ajustar la formación docente a esas respuestas. En caso de que la Educación Especial desaparezca, la preguntas serían ¿cuál es el educador capaz de atender a toda la diversidad y de diseñar apoyos educativos específicos para todo el estudiantado? ¿Cómo redirigir, entonces, en esa dirección los recursos que han sido hasta ahora propiedad exclusiva de la Educación Especial?

\section{Formatos internacionales de formación en Educación Especial}

En relación con lo que se ha tratado hasta ahora es interesante acercarse a ofertas de formación docente en Educación Especial que se han transformado en los últimos años, con la intención de conocer la forma en que vienen interpretando y asumiendo cambios relacionados con la educación inclusiva en distintos países y según se hace posible detectar mediante la información colgada en los sitios web de las diversas universidades estudiadas.

En los Estados Unidos, por ejemplo, no se identifica uniformidad en enfoques ni titulaciones entre las 420 universidades que ofrecen la carrera de Educación Especial. Mientras algunas universidades brindan la titulación de grado en el campo, en otras solo se observa que la formación refiere al grado de Magíster posterior a una formación generalista de magisterio, tal y como ocurre actualmente en la mayoría de países de la Unión Europea. Además, mientras un sector de la educación superior opta por una

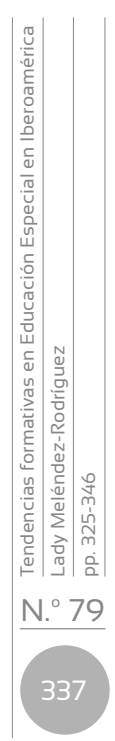


inclusión con alguna tendencia hacia la autogestión de las personas con discapacidad intelectual, como las que siguen al movimiento de Inclusion International, otras ponen énfasis en otro tipo de discapacidades y siguen enfoques más conservadores hacia la atención específica.

En América Latina, en cambio, hay países que han dictado una política nacional en cuanto a la formación docente en Educación Especial, con la intención de que esta se ajuste a la reorganización estatal de los servicios educativos, como sucede en México y Chile. Por su parte, la educación superior de otros países parece tener más autonomía en la toma de decisiones al respecto, como sucede en los casos de Colombia y Costa Rica.

Enseguida se ofrece un cuadro comparativo que incluye algunos datos sobre carreras en Educación Especial de distintos países, que han cambiado sus planes de formación en los últimos 10 años, siguiendo los pocos criterios que permitían esa comparación.

\begin{tabular}{|c|c|c|c|c|}
\hline Universidad & País & Grado o titulación & Duración & Enfoque \\
\hline $\begin{array}{l}\text { Frederick } \\
\text { University }\end{array}$ & Chipre & $\begin{array}{l}\text { Maestría en Educación } \\
\text { Especial }\end{array}$ & $\begin{array}{c}3 \\
\text { semestres }\end{array}$ & $\begin{array}{l}\text { Necesidades educativas } \\
\text { especiales (N.E.E.), } \\
\text { discapacidad con } \\
\text { orientación inclusiva } \\
\text { (integración) }\end{array}$ \\
\hline $\begin{array}{l}\text { Universidad } \\
\text { del Noreste }\end{array}$ & México & $\begin{array}{l}\text { Licenciatura en } \\
\text { Educación Especial }\end{array}$ & $\begin{array}{c}8 \\
\text { semestres }\end{array}$ & $\begin{array}{l}\text { Intervención a N.E.E. } \\
\text { con o sin discapacidad. } \\
\text { Relacionada con } \\
\text { los fundamentos } \\
\text { del movimiento de } \\
\text { integración educativa } \\
\text { que promueve el Sistema } \\
\text { Educativo Mexicano }\end{array}$ \\
\hline $\begin{array}{l}\text { Universidad } \\
\text { Católica del } \\
\text { Maule }\end{array}$ & Chile & $\begin{array}{l}\text { Licenciatura en } \\
\text { Educación Especial con } \\
\text { mención en Trastornos } \\
\text { del Lenguaje y } \\
\text { Discapacidad } \\
\text { Intelectual/Licenciatura } \\
\text { en Educación } \\
\text { Especial con mención } \\
\text { en Trastornos del } \\
\text { Lenguaje y Dificultades } \\
\text { del Aprendizaje }\end{array}$ & $\begin{array}{c}9 \\
\text { semestres }\end{array}$ & $\begin{array}{l}\text { Respuesta a las N.E.E y a } \\
\text { la diversidad para formar } \\
\text { comunidades inclusivas } \\
\text { desde el trabajo } \\
\text { interdisciplinario. }\end{array}$ \\
\hline $\begin{array}{l}\text { Australian } \\
\text { Catholic } \\
\text { University }\end{array}$ & Australia & $\begin{array}{l}\text { Bachelor of inclusive } \\
\text { education and disability } \\
\text { studies }\end{array}$ & $\begin{array}{c}4 \\
\text { semestres }\end{array}$ & $\begin{array}{l}\text { Derechos de la persona } \\
\text { con discapacidad, visión } \\
\text { social de la discapacidad, } \\
\text { autogestión, } \\
\text { empoderamiento, } \\
\text { dificultades en el } \\
\text { aprendizaje y apoyo } \\
\text { conductual positivo }\end{array}$ \\
\hline
\end{tabular}




\begin{tabular}{|c|c|c|c|c|}
\hline Universidad & País & Grado o titulación & Duración & Enfoque \\
\hline $\begin{array}{l}\text { Universidad } \\
\text { de Antioquia }\end{array}$ & Colombia & $\begin{array}{l}\text { Licenciatura en } \\
\text { Educación Especial }\end{array}$ & $\begin{array}{c}10 \\
\text { semestres }\end{array}$ & $\begin{array}{l}\text { Persona con } \\
\text { discapacidad desde } \\
\text { diversos sectores y } \\
\text { contextos de trabajo. } \\
\text { Interdisciplinariedad. }\end{array}$ \\
\hline $\begin{array}{l}\text { Universidad } \\
\text { Pedagógica } \\
\text { Nacional }\end{array}$ & Colombia & $\begin{array}{l}\text { Licenciatura en } \\
\text { Educación Especial }\end{array}$ & $\begin{array}{c}10 \\
\text { semestres }\end{array}$ & $\begin{array}{l}\text { Alteridad, diversidad, } \\
\text { sujeto de derechos, } \\
\text { propuestas educativas } \\
\text { para el cierre de brechas. }\end{array}$ \\
\hline $\begin{array}{l}\text { Universidad } \\
\text { Nacional }\end{array}$ & Costa Rica & $\begin{array}{l}\text { Licenciatura en } \\
\text { Educación Especial con } \\
\text { énfasis en Integración }\end{array}$ & $\begin{array}{c}10 \\
\text { semestres }\end{array}$ & Integración y N.E.E \\
\hline
\end{tabular}

Fuente: elaboración propia.

Es importante visibilizar que las distintas universidades justifican sus recientes cambios en la necesidad de ajustarse a las nuevas demandas de un educador especial inserto en contextos de educación inclusiva y de atención educativa a la diversidad. No obstante, sea por razones estructurales o ideológicas, a la mayoría de universidades le resulta imposible dejar de ver a la educación de la persona con discapacidad como el objeto de la profesión, que parece ensancharse hacia la diversidad en la atención a las necesidades educativas específicas que no son causa directa de una discapacidad, pero sin atreverse a ir más allá en el terreno de la diversidad.

Lo que sí parece haberse ampliado en los planes de formación de las carreras en Educación Especial son los espacios de acción. Mientras antes se reducían a centros específicos ahora se habla también de que los educadores especiales pueden ser docentes de apoyo en los centros educativos ordinarios, en proyectos comunitarios y en la atención con familias. Pero también se espera que sean investigadores permanentes y colaboradores efectivos en equipos interdisciplinarios, ampliando de esta manera sus oportunidades laborales.

\section{Perfil profesional del educador especial}

El perfil profesional del educador especial es difícil de conseguir en un formato oficial de país, al menos enunciado como tal. En Chile, por ejemplo, se llevó a cabo un proceso de construcción y validación de un extenso perfil en nivel nacional, que hoy orienta tanto los procesos de formación, como de selección, contratación y evaluación del desempeño docente. (Godoy, Otondo y Rey, 2016). Pero no se ha identificado un ejercicio similar en ningún otro país de América Latina ni en España. 
Por lo tanto, los planes de formación de la carrera en Educación Especial de distintas universidades son reflejo de una labor interna a la gestión de las propias carreras, que deja ver la tendencia ideológica del centro de estudios y de su propia interpretación autónoma de lo que debe ser un educador especial a la luz de las demandas del contexto y de los ideales de la educación inclusiva. La fusión de ambas perspectivas hace poner el peso nuevamente en la atención educativa a las personas que requieren apoyos educativos específicos, pero esta vez con una aspiración hacia la educación inclusiva y al trabajo interdisciplinario e investigador, que era difícil de hallar en los perfiles docentes de hace una década para atrás.

En otro orden de ideas, los perfiles de egreso que se enuncian en los documentos públicos acerca de las carreras de Educación Especial son planteados a grandes rasgos por lo general. Eso impide realizar un desglose en elementos, que luego de paso a un análisis curricular y a evaluar si los logros del conjunto de actividades académicas refieren a todas las necesidades de formación que documenta el perfil o si algunas están quedando fuera.

Al respecto, tal generalidad lleva a inferir que los perfiles no han sido sometidos a procesos rigurosos de validación contextual, por lo que también, las dimensiones de pertinencia y calidad se vuelven difíciles de determinar en las carreras internamente; pero también desde la dimensión externa, para los procesos de acreditación y, por supuesto, para garantizar que atendemos a un proyecto país con el tipo y nivel de profesionales que estamos ofreciendo y a los profesionalespara asegurarles que tienen un espacio o que pueden crear uno nuevo donde desempeñarse laboralmente.

Por lo tanto, estamos urgidos de perfiles profesionales en Educación Especial que dejen ver a qué tipo de país estamos aspirando, qué papel juega el educador especial en ese proyecto, qué competencias debe desarrollar para ejercerlo; pero, además, qué capacidad crítica le va a permitir ser un evaluador propositivo para el mejoramiento de esos mismos procesos, para leer las transformaciones del contexto y trascenderse a sí mismo adaptándose con flexibilidad a nuevas demandas culturales.

\section{Análisis epistemológico de la Educación Especial: la experiencia costarricense}

Con una honda preocupación por el futuro de la Educación Especial y del educador especial de cara a las demandas de la educación inclusiva, como se explica en Castillo, et ál. (2018), en los años 2015 y 2016 Costa Rica, mediante la convocatoria de la Universidad Estatal a Distancia, inició una jornada de análisis a la que se sumaron el resto de universidades públicas, 
el Ministerio de Educación Pública, el colegio profesional que agremia a los educadores (Colypro), la agencia nacional de acreditación de la educación superior (Sinaes), familias, personas usuarias de servicios de Educación Especial y educadores de todo el país, además de expertos internacionales. Durante dos grandes jornadas y mediante ponencias, paneles de expertos, debates bajo la metodología meta acción, se intentó dar respuesta a tres preguntas: ¿qué es la Educación Especial en este momento histórico? ¿Hacia dónde debe ir la Educación Especial en los próximos años? Y ¿Cuál debe ser el rol del educador especial en el futuro cercano?

Entre los principales hallazgos y conclusiones se encuentran el hecho de que países donde prácticamente se había abolido la Educación Especial, dado que se considera enemiga de la inclusión, no han dado cuenta de mejores logros hacia la educación inclusiva en los últimos años, y que aquellas personas que requerían apoyos extensos y generalizados estaban corriendo el riesgo de quedar excluidas de las ofertas educativas.

Por otra parte, se acordó que en Costa Rica la Educación Especial debe continuar, en la medida que esta ha liderado las distintas acciones por la educación inclusiva que se han desarrollado en el país. Pero,

[...] es necesario sacar a la Educación Especial de esa concepción reduccionista e instrumental que la ha encerrado dentro de un conjunto de apoyos para una población específica definida desde el déficit. Es necesario elevar la Educación Especial a un merecido rango de disciplina o campo de estudio donde la adjetivación "especial" no refiera a aquello que se sale de la norma, sino a aquello que sea capaz de catapultar la superación de barreras para el aprendizaje y la participación, capaz de izar el derecho a la educación de calidad, equitativa y con sostenibilidad para todas y todos los estudiantes desde el curriculum, la gestión y la práctica educativas, capaz de sostener un conocimiento actualizado mediante la investigación permanente por el mejoramiento (Castillo, et ál., 2018, p. 16).

Así, las jornadas permitieron redefinir a la Educación Especial en Costa Rica, diciendo de esta que se trata de

[...] la rama del conocimiento que se encarga de construir, organizar, liderar, proponer y practicar -colaborativamente- estrategias pedagógicas capaces de atender a la diversidad y catapultar la superación de barreras para el aprendizaje y la participación, incluso en las personas que requieren apoyos extensos y generalizados; así como de mantener un conocimiento actualizado mediante la investigación permanente y la reflexión de su propia práctica (Castillo, et ál. 2018, p. 26).

$Y$, define al educador especial como el profesional capaz de asumir cada una de las funciones y actitudes que se incluyen en la definición de la disciplina. 
Este ejercicio realizado en Costa Rica muestra que los principios de la educación inclusiva son válidos para todas las sociedades, pero que el ejercicio del derecho a una educación con equidad y calidad, que alude a una atención educativa a la diversidad y a la construcción de estrategias para la superación de barreras para el aprendizaje y la participación, debe vivirse de manera atenta al momento histórico y los recursos con que cuenta cada sociedad. De tal forma que en el pasado podía verse a la Educación Especial como la antítesis de la educación inclusiva, pero actualmente, al menos en Costa Rica, ambas han desarrollado una relación simbiótica en la que una no es capaz de sostenerse separada de la otra.

\section{Algunas conclusiones para empezar}

» La educación inclusiva es un organismo vivo y la Educación Especial un recurso vivo de gran potencial para mantenerla; por lo que, para desarrollarse, deben evolucionar al unísono y en sintonía.

» La Educación Especial y su misión deben encontrar sentido en el contexto de un proyecto país, que pretende su desarrollo desde oportunidades equitativas para todos sus habitantes, con sus identidades personales y culturales.

» Más allá de un conjunto de apoyos, la Educación Especial debe ser definida como una disciplina, lo mismo que su objeto de estudio, su objeto de trabajo y, así, el objeto de la profesión docente en este campo.

» La Educación Especial ha sido abolida en algunos países, como es el caso de España, pero aún no se ven los beneficios de esta decisión de cara a la educación inclusiva y, en su defecto, parece que las personas que requieren apoyos extensos y generalizados no encuentran lugar en los servicios disponibles desde la inclusión.

» La educación finesa atribuye sus altos estándares de calidad a la capacidad de prevenir las dificultades escolares antes de que se presenten, así como de atender las dificultades de manera colaborativa mediante proyectos de centro. Funciones que son lideradas por los educadores especiales.

» La Educación Especial debe ser redefinida en cada sociedad bajo los principios de la educación inclusiva previo a poder definir el perfil profesional docente capaz de atender a los servicios y a sus beneficiarios.

» Los planes de formación que plantean ofertas recientes en Educación Especial, ante la imposibilidad de asumir todo lo que se refleja en la educación inclusiva y la atención educativa a la diversidad, 
han optado por recortar su propio espacio de acción. De forma tal, que los han acomodado a la atención a necesidades educativas específicas asociadas o no a una discapacidad, pero no pretenden ir más allá.

»En los planes de formación se han diversificado los espacios de acción donde se espera que el futuro educador especial labore. Mientras antes su trabajo se circunscribía a los centros específicos, ahora se habla de centros educativos ordinarios, proyectos comunitarios, equipos de investigación y de atención interdisciplinaria.

» Con excepción de Chile, los países no cuentan con un perfil profesional oficial de la Educación Especial que permita contraponer los perfiles de egreso propuestos en los planes de formación con una propuesta nacional, que oriente cuál debe ser el enfoque y cuáles las competencias fundamentales que debe poseer un educador especial.

» Los perfiles de egreso de las carreras de Educación Especial están planteados a grandes rasgos $y$, al parecer, sin procesos rigurosos de validación. Esto impide que la carrera pueda hacer un análisis curricular que le permita valorar si está cumpliendo con todos los requerimientos de formación.

\section{Referencias}

Australian Catholic University. (2018, 15 de octubre). Bachelor of inclusive education and disability studies. https:/www.hotcoursesabroad.com/ study/course/australia/bachelor-of-inclusive-education-and-disability-studies/94057/program.html?nationCode=43 \&nationCntryCode $=43$

Castillo, K., Deliyore, R., González, V., Madriz, L., Marín, M.G., Meléndez, L., Montenegro, F., Rodríguez, R. Segura, M. y Solórzano, J. (2018). Análisis epistemológico de la Educación Especial en Costa Rica. Actualidades Investigativas en Educación, 8(2), 1-28.

Echeíta, G. (2016, 21-22 de abril). El escenario mundial de la Educación Especial y del (la) educador(a) especial. I Jornada de Análisis Epistemológico la Educación Especial en Costa Rica, Cenarec.

Florin, L. (2014). La Educación Especial en la era de la inclusión: ¿El fin de la Educación Especial o un nuevo comienzo? Difusión, Formación e Investigación para la Diversidad Funcional, 7(2), 27-36.

Frederick University. (2018, 15 de octubre). Maestría en Educación Especial. https:/www.master-maestrias.com/Graduado-en-Educaci\%C3\%B3n-Especial/Chipre/Frederick-University/ 
Godoy, M., Otondo, M. y Rey, V. (2016). Formación de profesores/profesoras diferenciales: Desde la mirada de las Universidades pertenecientes al Consejo de Rectores de Chile. En V. Alves y R. Vargas (Coords.), Educación inclusiva en América Latina: políticas, investigaciones y experiencias. Brasil: Intertexto y México: Capub.

Meléndez, L (2004). Diversidad y equidad: paradigma educativo urgente para la Costa Rica en vías de desarrollo. Revista Parlamentaria, 12(2).

Meléndez, L. (2010, 27-29 de mayo). El panorama latinoamericano de las prácticas educativas inclusivas. Conferencia presentada en el VI Encuentro Internacional de Inclusión Educativa: ¿y de la ética qué? Costa Rica.

Meléndez, L. (2016, 12 de marzo). El rol del docente de apoyo en las prácticas educativas inclusivas: visión latinoamericana. Conferencia presentada en el Congreso "Inclusión Educativa y Curriculum Inclusivo. Balances y Perspectivas". Venezuela: Universidad José Antonio Páez.

Meléndez, L. (2016). La educación Especial en Costa Rica. Fundamentos y evolución. Costa Rica: Euned.

Meléndez, L. y Hernández, E. (2016). Trayectoria y estado actual de la Educación Especial en Costa Rica. En V. Alves y R. Vargas (Coords.) Educación inclusiva en América Latina: políticas, investigaciones y experiencias (pp. 123-143). Brasil: Intertexto y México: Capub.

MEP (2005). La atención a las necesidades educativas especiales en Costa Rica: preguntas y respuestas sobre la atención a las necesidades educativas especiales. Costa Rica: Imprenta Nacional.

ONu (1948). Declaración Universal de Derechos Humanos. http://www. ohchr.org/EN/UDHR/Documents/UDHR_Translations/spn.pdf

ONU (1960). Convención relativa a la Lucha contra las Discriminaciones en la esfera de la Enseñanza. http://portal.unesco.org/es/ev.phpURL_ID=12949\&URL_DO=DO_TOPIC\&URL_SECTION=201.html

ONU (1979). Convención sobre la eliminación de todas las formas de discriminación contra la Mujer. http://www.un.org/womenwatch/daw/ cedaw/text/sconvention.htm

ONU (1989). Convención sobre los Derechos del Niño. http://www.unicef. org/argentina/spanish/7.-Convencionsobrelosderechos.pdf

ONU (2006). Convención de Derechos de las Personas con Discapacidad. http://www.un.org/esa/socdev/enable/documents/tccconvs.pdf

ONU (2007). Declaración de las Naciones Unidas sobre los Derechos de los Pueblos Indígenas. http://www.un.org/esa/socdev/unpfii/documents/DRIPS_es.pdf

ONU (2010). Resolución de la Asamblea General de las Naciones Unidas sobre el Derecho a la Educación en Situaciones de Emergencia. 
http://s3.amazonaws.com/inee-assets/resources/UN_Resolution_ Education_in_Emergencies.pdf

Sabel, C., Saxenian, A. L., Miettinen, R., Hull, P. y Hautamäki, J. (2010). Individualized Service Provision in the New Welfare State: Lessons from Special Education in Finland. Helsinki: Sitra.

Unesco (1990). Declaración Mundial de Educación para Todos. Marco de Acción Asociado. Tailandia: Autor.

Unesco (2014). Acuerdo de Mascate. http://www.edupost2015.cat/ wp-content/uploads/2015/11/El-Acuerdo-de-Mascate.pdf

Unesco (2014). Declaración de Lima. http://www.unesco.org/new/fileadmin/MULTIMEDIA/FIELD/Santiago/pdf/Declaracion-de-Lima-31-102014-ESP.pdf

Unesco (2015). Incheon Declaration. Education 2030: Towards inclusive and equitable quality education and lifelong learning for all. http:// uis.unesco.org/en/document/education-2030-incheon-declaration-towards-inclusive-equitable-quality-education-and

Universidad de Antioquia. (2018, 15 de octubre). Licenciatura en Educación Especial. http://portal.udea.edu.co/wps/wcm/connect/udea/ a9d8b215-1518-4f5f-9ec6-26e05af7eda5/plan-estudios-lic-edu-especial.pdf?MOD=AJPERES

Universidad Católica del Maule. (2018, 15 de octubre). Licenciatura en Educación Especial. http://portal.ucm.cl/carreras/pedagogia-educacion-especial

Universidad del Noreste. (2018, 15 de octubre). Licenciatura en Educación Especial. http://www.universia.net.mx/estudios/universidad-noreste/educacion-especial/st/204176

Universidad Nacional. (2018, 15 de octubre). Licenciatura en Educación Especial. https://www.una.ac.cr/index.php/m-oferta-academica/educacion-especial-bachillerato-y-licenciatura

Universidad Pedagógica Nacional. (2018, 15 de octubre). Licenciatura en Educación Especial. http://educacion.pedagogica.edu.co/ vercontenido.php? $\mathrm{idp}=395 \& \mathrm{idh}=397 \& \mathrm{idn}=11736$

Vargas, R. y Alves, V. (Coords.) (2016). Educación inclusiva en América Latina. Políticas, investigaciones y experiencias. México: Capub/Capes/Intertexto.

Vélez, L. (2016, 21 - 22 de abril). El escenario latinoamericano de la Educación Especial y del (la) educador(a) especial. I Jornada de Análisis Epistemológico la Educación Especial en Costa Rica, Cenarec. 